\title{
MODELAGEM MATEMÁTICA SOB A PERSPECTIVA SÓCIO-CRÍTICA: UMA PROPOSTA DIDÁTICA ABORDANDO O GERENCIAMENTO DE RESÍDUOS SÓLIDOS NO MUNICÍPIO DE PORTO ALEGRE
}

DOI: $10.37702 / 2175-957 X . C O B E N G E .2021 .3729$

Matheus Erpen Benincá - matheuseb@hotmail.com

Universidade Federal do Rio Grande do Sul

Rua Anita Garibaldi 500

90450-000 - Porto Alegre - RS

Polyana Perosa - polyperosa@hotmail.com

Universidade Federal do Rio Grande do Sul

Avenida Osvaldo Aranha 340

90035-190 - Porto Alegre - RS

Amanda Fuhr Molling - amandafmolling@hotmail.com

Universidade Federal do Rio Grande do Sul

Rua Catarina rausch 116

93950-000 - Dois irmãos - RS

ANDERSON BORGES MODENA - andersonbborgesmodena@gmail.com Universidade Federal do Rio Grande do Sul

R. DEPUTADO DORIVAL C. DE OLIVEIRA, 16781678

94960-160 - CACHOEIRINHA - RS

Jônata Martini - jonatamartini17@gmail.com

Universidade Federal do Rio Grande do Sul

Rua Barão do Amazonas 273

90670-003 - PORTO ALEGRE - RS

Bruno Löff Ferreira Leite - engbrunolfleite@gmail.com

Universidade Federal do Rio Grande do Sul

Servidão da Graça, Quarta travessa 57

88058-790 - Florianópolis - SC

LEANDRA ANVERSA FIOREZE - leandra.fioreze@gmail.com

Universidade Federal do Rio Grande do Sul

Rua Nicola Mathias Falci 50 
91410-330 - Porto Alegre - RS

Resumo: Este artigo aborda uma proposta didática interdisciplinar, apresentada a estudantes do curso de Licenciatura em Matemática da Universidade Federal do Rio Grande do Sul, construída sob o referencial teórico da Modelagem Matemática na perspectiva sócio-crítica. Inicialmente, é feita uma breve revisão bibliográfica elencando as principais características e objetivos desta metodologia de ensino, com foco especial na formação cidadã dos alunos e professores. Com base nos Parâmetros Curriculares Nacionais, evidenciou-se a importância de temas socioambientais serem abordados em sala de aula de forma transversal, o que inclui as aulas de matemática. Neste contexto, foi proposto um planejamento de aula, com a participação de um Engenheiro Civil convidado, que aborda o gerenciamento de resíduos sólidos no município de Porto Alegre, visando a discussão sobre um tema de relevância socioambiental, permitindo que o aluno seja sujeito ativo da sua aprendizagem através da reflexão sobre sua realidade $e$ da proposição de ações transformadoras. São discutidas algumas relações entre a atividade proposta e os referenciais teóricos apresentados. Após, é feito um relato de um experimento piloto, realizado em uma turma da disciplina de Educação Matemática e Docência III, evidenciando-se as discussões e rotas de modelagem que surgiram durante a atividade, e elencando algumas potencialidades didáticas em possíveis aplicações no Ensino Médio. Por fim, discute-se a importância de a formação do professor de matemática incluir o estudo de tendências de educação que abranjam temas transversais, bem como as vantagens mútuas advindas de aproximações entre os cursos de Engenharia e Licenciatura.

Palavras-chave: Modelagem Matemática, perspectiva sócio-crítica, gerenciamento de resíduos sólidos, interdisciplinaridade, Engenharia, Licenciatura. 


\section{MODELAGEM MATEMÁTICA SOB A PERSPECTIVA SÓCIO-CRÍTICA: UMA PROPOSTA DIDÁTICA ABORDANDO O GERENCIAMENTO DE RESÍDUOS SÓLIDOS NO MUNICÍPIO DE PORTO ALEGRE}

\section{INTRODUÇÃO}

Neste trabalho, discorre-se sobre a tendência em educação matemática conhecida como Modelagem Matemática, com foco na perspectiva sócio-crítica, que tem como principal objetivo estimular a discussão coletiva sobre temas socioambientais, a fim de instruir e debater sobre temas recorrentes na vida cotidiana do aluno.

Os Parâmetros Curriculares Nacionais (BRASIL, 1998) preveem a abordagem de temas transversais na escola, sendo divididos em cinco temáticas: Ética; Pluralidade Cultural; Meio Ambiente; Temas Locais e Orientação Sexual. Neste contexto, apresenta-se uma proposta didática abordando o gerenciamento de resíduos sólidos no município de Porto Alegre, e relaciona-se este tema com a Modelagem Matemática sob a perspectiva sócio-crítica. O planejamento foi feito inicialmente para um público-alvo composto por alunos do $3^{\circ}$ ano do Ensino Médio de escolas públicas de Porto Alegre, de forma que as temáticas Meio Ambiente e Temas Locais sejam simultaneamente contempladas. Alternativamente, a proposta também pode ser aplicada em turmas de cursos de Licenciatura, visando a formação de professores para a Educação Básica. Entre os objetivos da proposta, destaca-se a formação cidadã dos alunos e professores, visando a conscientização ambiental, a diminuição da geração de resíduos e a sua correta destinação.

A proposta didática foi elaborada e apresentada na disciplina de Educação Matemática e Docência III, na Faculdade de Educação da Universidade Federal do Rio Grande do Sul, no segundo semestre de 2019, por estudantes de Licenciatura em Matemática, com a participação de um Engenheiro Civil convidado'. Nesta disciplina também foi realizado um experimento piloto da atividade proposta com os próprios estudantes de Licenciatura em Matemática, sobre o qual são analisados resultados e elencadas algumas potencialidades didáticas, bem como discutida a importância da aproximação entre os cursos de Engenharia e Licenciatura.

\section{MODELAGEM MATEMÁTICA}

A Modelagem Matemática é uma tendência em educação que se baseia nas ideias de vários autores, entre eles Bassanezi (2015), Barbosa (2001) e Burak (1992). Ela é usada para tentar explicar e compreender fenômenos naturais, que podem estar relacionados com diversas áreas do conhecimento. Alguns exemplos de aplicações podem ser observados na modelagem do crescimento populacional de cidades, no planejamento e controle do cultivo de espécies vegetais, na modelagem da dispersão de poluentes na atmosfera, na análise do gerenciamento de resíduos etc. É interessante observar que muitos desses exemplos também estão diretamente relacionados com a Engenharia.

Burak (1992) argumenta que a Modelagem Matemática, quando aplicada à educação, pode ser compreendida como uma estratégia de ensino e aprendizagem que possibilita ao estudante abordar conteúdos matemáticos a partir de fenômenos de sua

${ }^{1}$ O Engenheiro Civil convidado, Bruno Löff Ferreira Leite, é mestrando no Programa de Pós-Graduação em Engenharia Civil: Construção e Infraestrutura (PPGCI/UFRGS), onde pesquisa sobre gerenciamento de resíduos e compostagem. 
realidade. Ela permite uma inversão do modelo tradicional de ensino, visto que por meio da modelagem selecionam-se primeiramente os problemas e, destes, emergem os conteúdos matemáticos que serão utilizados para resolvê-los.

Práticas educativas embasadas na Modelagem Matemática requerem muita atenção e flexibilidade por parte do professor, que deve estar disposto a deixar seu protagonismo de lado e assumir o papel de mediador, uma vez que neste modelo de ensino o aluno é o principal protagonista.

\subsection{Modelagem matemática sob a perspectiva sócio-crítica}

A perspectiva sócio-crítica da Modelagem Matemática tem como principal objetivo a condução de atividades de modo que o aluno, a partir do uso de conceitos matemáticos, possa aprofundar seus conhecimentos sobre o mundo no qual está inserido. Segundo Silva e Kato (2012), essa é uma forma de o aluno tomar posicionamento decisivo na sociedade, tornando-se não apenas um mero espectador dos eventos socioculturais que o cercam, mas sim um agente ativo, capaz de criticar as diversas estruturas presentes no cotidiano, tomar decisões em questões de debate e propor soluções de problemas.

A Modelagem Matemática na perspectiva sócio-crítica possui elementos que a caracterizam, os quais direcionam o andamento de uma atividade em sala de aula: participação ativa do aluno na construção do modelo; participação ativa do aluno na sociedade; matematização de um problema supostamente não-matemático e atuação do professor como mediador durante todo o processo.

Com sua participação ativa, o aluno trabalha em conjunto com um grupo para decidir como desenvolver o modelo, tornando assim a sala de aula um ambiente democrático.

As atividades de Modelagem Matemática, na perspectiva socio-crítica, fazem da sala de aula um espaço em que todos podem participar igualmente, expondo seus pensamentos e incentivando o respeito pelas ideias dos outros, permitindo que observem como a Matemática e o modelo matemático construído podem servir para analisar e tomar decisões sobre determinado problema (SILVA; KATO, 2012, p. 830).

As temáticas abordadas geralmente envolvem os interesses dos educandos, podendo gerar uma participação ativa do aluno na atividade e proporcionando a continuidade do seu desenvolvimento para além da sala de aula. "[...] essas ideias são entendidas e discutidas de tal forma que os participantes problematizam sua extensão para o contexto social" (ARAÚJO, 2009. p. 59).

O problema não-matemático da realidade advém do interesse dos alunos por um determinado tema. Para a construção do modelo, os alunos usam seus conhecimentos prévios para proporem uma resolução da situação-problema, contudo ela não precisa necessariamente ter uma solução. De acordo com Jacobini e Wodewotzki (2006, p. 73), “o professor oferece ao aluno a oportunidade de conviver com conteúdos vivos, práticos, úteis e com bastante significado".

O professor atua como mediador em sala de aula, estimulando a exposição e a argumentação das ideias em questão, ocupando assim um espaço importante para tornar possível uma reflexão profunda do problema que está sendo tratado. Deste modo, muitas vezes o professor pode vir a ultrapassar e superar suas próprias concepções prévias, por considerar as diversas realidades dos alunos, tornando assim possíveis os debates que vão para além da sala de aula. Com os agentes inseridos nesse ambiente reflexivo, Orey e Rosa (2007, p.198) afirmam que "[...] a educação direcionada para a eficiência sócio-crítica adota práticas pedagógicas não-tradicionais, pois elas colocam o aluno no centro do processo de ensino-aprendizagem". 
Neste contexto, segundo Silva e Kato (2012), o potencial da Modelagem Matemática não fica retido apenas ao campo da aprendizagem, mas busca também a formação cidadã dos alunos e inclusive dos professores.

Segundo Skovsmose (2007), a educação matemática crítica visa a preparação para o exercício da cidadania, a compreensão crítica do mundo e a transformação da realidade. A Modelagem Matemática sob a perspectiva sócio-crítica, conforme sugerido por Barbosa (2001), utiliza-se das ideias da educação matemática crítica no contexto da modelagem, buscando aplicar a matemática a problemas reais, interpretando-os criticamente, através do pensamento reflexivo.

De acordo com Araújo (2009), a Modelagem Matemática na perspectiva sócio-crítica deve promover a atuação crítica dos alunos na sociedade por meio do conhecimento matemático, de forma que possam reconhecer e valorizar sua cultura e sua realidade. Araújo propõe, ainda, que as atividades de Modelagem sejam utilizadas como suporte para discussões em sala de aula, que devem ser problematizadas para o contexto social. Assim, promove-se a atuação crítica dos alunos na sociedade, visando a sua emancipação enquanto cidadãos.

Se trabalharmos com Modelagem Matemática na educação matemática e não discutirmos questões como o uso da matemática na sociedade, a ideologia da certeza e o poder formatador na matemática, podemos estar contribuindo para a manutenção de uma sociedade injusta ou até mesmo reforçando tal situação (ARAÚJO, 2009, p. 64).

Portanto, na perspectiva sócio-crítica tem-se como foco a preparação dos alunos para o exercício da cidadania, incentivando-os a buscarem soluções práticas para situações-problema da sociedade, considerando seus valores e crenças e capacitando-os a resolver problemas do dia a dia. A formação do aluno deve ser direcionada com o objetivo de transformá-los em indivíduos "flexíveis, adaptáveis, reflexivos, críticos e criativos" (OREY; ROSA, 2007 p.199).

\subsection{Temas sociais na escola}

A escola é um ambiente formador do aluno enquanto cidadão, preparando-o para uma vida em sociedade, na qual é necessário um amplo conhecimento dos mais diversos temas que compõem os debates presentes no cotidiano. De acordo com Ueno e Moraes (2007), os temas sociais devem ser tratados como novos conhecimentos e trabalhados como centro das preocupações da sociedade.

Para que o trabalho nas salas de aula de matemática implique aprendizagem de conceitos, favorecendo a apropriação, por parte dos alunos, dos conhecimentos necessários à sua formação, torna-se indispensável aproximar os conteúdos matemáticos aos temas significativos do mundo atual e incluir questões vinculadas à realidade e interesse dos alunos (UENO; MORAES 2007, p. 224).

Para tanto, os PCN (BRASIL, 1998) estipularam diversos temas propostos para serem trabalhados nas escolas, enfatizando a necessidade da presença dos mais diversos debates em sala de aula, como "[...] ética, meio ambiente, trabalho e consumo, saúde, pluralidade cultural e orientação sexual, [...] tendo a ética como eixo norteador, que leva à reflexão crítica e à construção da cidadania" (UENO; MORAES 2007, p. 224).

Consequentemente, a perspectiva sócio-crítica da Modelagem Matemática toma grande importância neste processo de formação cidadã do aluno para além das quatro paredes da sala de aula, transformando o que está fora da escola em uma extensão da sala de aula. Fato que se deve, segundo Jacobini e Wodewotzki (2006), às investigações 
realizadas no grande grupo pelos estudantes e ao envolvimento direto com os debates da comunidade, oportunizando assim um pensamento reflexivo aprofundado das situaçõesproblema desenvolvidas em aula.

Lançando mão dessas prerrogativas, é visível a suma importância dos temas sociais nas escolas, os quais podem servir como incentivo para grandes debates e construções em sala de aula, tendo o aporte matemático para as diversas conclusões do grande grupo.

\subsection{Gerenciamento de resíduos}

É demasiado comum, no Brasil, o descarte inadequado de resíduos sólidos, tanto a nível domiciliar quanto industrial. É recorrente encontrarmos resíduos espalhados pelas ruas das cidades, por córregos e rios, bem como observarmos bueiros entupidos devido à grande quantidade de plásticos, papéis, entre outros resíduos que não são descartados de maneira correta. Assim, o tema é notadamente sensível a todos os cidadãos.

O presente trabalho busca relacionar a problemática de resíduos sólidos, especificamente no município de Porto Alegre, com uma proposta didática de Modelagem Matemática sob a perspectiva sócio-crítica. Para tanto, foram buscadas algumas informações preliminares a fim de situar e conscientizar os participantes da atividade, alunos e professores, muito embora o trabalho de pesquisa sobre a situação atual do gerenciamento de resíduos no município seja parte integrante e importante da atividade proposta.

A partir do início dos anos 1990, o depósito dos resíduos em lixões passou a ser proibido em Porto Alegre. Dessa forma, juntamente com o Departamento Municipal de Limpeza Urbana - DMLU - foi criado no município o Sistema Integrado de Resíduos Sólidos, com o objetivo de reduzir o impacto ambiental gerado. Contudo, em 2009 ainda não se notava uma grande eficácia na reciclagem:

Conforme dados do DMLU, a população do município de Porto Alegre gera em torno de 1600 toneladas por dia de lixo. Dessas 1600 toneladas, estima- se que $900 t$ são de resíduos domiciliares, sendo que 600t são de matéria orgânica e 300t são matéria inorgânica. A coleta seletiva formal, feita pelo DMLU, recolhe aproximadamente 60 toneladas de resíduos sólidos recicláveis, o chamado lixo seco. Logo, observa-se que existem cerca de 240 toneladas de lixo recolhidos diariamente que poderiam ser reciclados (HELLER, 2009, p.11).

Os dados acima descritos são desanimadores, uma vez que, na época, perdia-se a oportunidade de coletar diariamente 240 toneladas de resíduos com potencial de reciclagem. O cenário aparenta não ter se modificado significativamente na última década, visto que, em 2020, o DMLU apresentou um levantamento na Câmara Municipal de Porto Alegre que apontava 61 toneladas de resíduos sólidos recolhidas diariamente para reciclagem (SUPTITZ, 2020).

Outro problema que afeta diversas cidades do país é a inexistência de separação dos resíduos nas próprias residências, muitas vezes proveniente da falta de informação e conscientização. É recorrente que pessoas não saibam a destinação correta do óleo de cozinha ou de pilhas e baterias, por exemplo. Nesse contexto, ressalta-se que o website do $\mathrm{DMLU}^{2}$ traz informações interessantes sobre reciclagem, compostagem, separação de resíduos etc. Contudo, observa-se que, para gerar um impacto transformador, essas informações precisam ser divulgadas de forma mais direta à população, inclusive em espaços educativos. Assim, atividades em sala de aula podem incentivar que alunos se apropriem dessas informações e de outros conhecimentos a serem pesquisados,

${ }^{2}$ Portal da prefeitura de Porto Alegre. Departamento Municipal de Limpeza Urbana. Disponível em: https://www2.portoalegre.rs.gov.br/dmlu/. Acesso em: 10 maio 2021. 
transformando-se em agentes ativos na busca por uma maior conscientização social sobre a geração, separação e destinação de resíduos.

Uma questão importante a ser abordada em práticas educacionais envolvendo o gerenciamento de resíduos sólidos é o caminho percorrido por eles até sua destinação final. É muito comum jogar um resíduo no lixo e esquecer de sua existência, como se ele tivesse miraculosamente desaparecido, e todo o problema sido resolvido. Porém, o ato de jogar algo no lixo é apenas o início de uma longa jornada. Em Porto Alegre, os resíduos sólidos são recolhidos primeiramente por caminhões de coleta domiciliar, e então são conduzidos até a Estação do Transbordo, que fica na Lomba do Pinheiro. Só depois deste trajeto preliminar que grande parte desses resíduos é levada até o aterro sanitário de Minas do Leão, localizado a cerca de $100 \mathrm{~km}$ da Estação de Transbordo. Todo esse percurso e o próprio acúmulo de resíduos no aterro sanitário geram uma série de impactos ambientais, que podem ser quantificados, avaliados e diagnosticados fazendo-se uso da Modelagem Matemática.

\section{PLANEJAMENTO DE AULA}

Foi realizado um planejamento para aplicar as ideias da Modelagem Matemática sob a perspectiva sócio-crítica em sala de aula. O público-alvo consiste em alunos do $3^{\circ}$ ano do Ensino Médio, mas com algumas adaptações a atividade também pode ser aplicada em disciplinas do nível superior, especialmente na formação de professores nos cursos de Licenciatura, ou até mesmo nas Engenharias. A temática escolhida foi a geração e destinação de resíduos urbanos, com os objetivos de promover o debate acerca da destinação dos resíduos sólidos, estimular que os alunos desenvolvam estratégias para a redução da geração de resíduos e que reflitam sobre a destinação correta dos resíduos por eles gerado. Para tanto, planejou-se convidar um Engenheiro e Pesquisador na área de resíduos para iniciar a discussão, que pode ficar responsável por trazer dados e informações técnicas pertinentes acerca da geração e destinação de resíduos sólidos em Porto Alegre.

Numa segunda etapa, o planejamento prevê que seja realizada a entrega de dados que foram debatidos durante a conversa com o Engenheiro para que seja realizada uma análise crítica. Para tanto, os alunos podem ser divididos em quatro grupos, com o intuito de que cada grupo analise um conjunto específico de dados e que ao final apresente suas conclusões para os colegas. Preferencialmente, deve ser disponibilizado um laboratório de informática para que seja possível pesquisar dados complementares e/ou utilizar softwares de matemática. Abaixo são elencadas sugestões de temas a serem discutidos:

Grupo 1: proposição de soluções para reduzir a geração de resíduos e destiná-los corretamente, como por exemplo utilizando reciclagem, compostagem e outros; bem como avaliar maneiras de operacionalizar essas soluções.

Grupo 2: estimar a geração de resíduos por pessoa, considerando a população do município de Porto Alegre, em diferentes intervalos de tempo. Comparar unidades utilizadas com o volume de uma lixeira comum, fazer a análise crítica do que significa essa quantidade de resíduos.

Grupo 3: estudar o aterro de Minas do Leão, avaliar sua capacidade, tempo de "vida útil", e o que será feito com ele após a desativação, bem como problemas ambientais que pode gerar. Quantificar os resíduos sólidos recebidos e as emissões de poluentes.

Grupo 4: estudar o transporte dos resíduos sólidos, incluindo o deslocamento até a estação de transbordo e posteriormente até o aterro. Calcular a quantidade de profissionais envolvidos, os custos para o município, a quantidade de combustível consumida, o impacto ambiental que gera. 
Após, deve ser disponibilizado um tempo para que os grupos debatam entre si sobre os temas pesquisados. Nessa etapa, os professores buscarão fazer mediações nos debates levantados pelos alunos e orientarão possíveis alterações nos roteiros de trabalho dos grupos, que devem ser flexíveis, indo de acordo com o interesse dos participantes.

Por fim, devem ser apresentados os resultados e soluções propostos pelos grupos em um novo debate, agora com toda a turma. Cada grupo deve expor seus resultados, apresentando seus argumentos e posicionamentos frente às situações, abrindo-se para novas possíveis interpretações e indagações dos outros grupos.

Esse planejamento utiliza diretamente os fundamentos teóricos da Modelagem Matemática sob a perspectiva sócio-crítica anteriormente elencados. Todos geramos resíduos, mas nem sempre temos consciência da quantidade gerada nem tampouco de sua destinação. Nosso intuito é utilizar a matemática - mais especificamente a Modelagem Matemática - como instrumento para compreensão e conscientização acerca da geração, separação, destinação, reutilização, compostagem e reciclagem de resíduos. Qual a importância de medidas alternativas que mitiguem os impactos ambientais? Para onde vai o resíduo doméstico coletado depois que sai de nossas casas? Qual a quantidade de resíduo gerada em uma cidade como Porto Alegre? Quais soluções para minimizar os problemas ambientais gerados? Podemos transformar a realidade com estas soluções?

\section{ANÁLISE E DISCUSSÃO DOS RESULTADOS}

A atividade foi aplicada em sala de aula na forma de um experimento piloto com os alunos da disciplina de Educação Matemática e Docência III, da Faculdade de Educação da UFRGS, onde executou-se o plano de aula desenvolvido com algumas adaptações, em razão do tempo reduzido: o planejamento fora feito para uma sequência de aulas, enquanto o experimento piloto foi realizado em um único encontro com 3 horas de duração. Os resultados discutidos neste artigo serão analisados com base nesse experimento piloto.

Começando pela palestra inicial do engenheiro Bruno, a turma foi dividida em grupos e convidada a pesquisar e debater sobre os 4 temas propostos no plano. Nesta etapa, os autores atuaram como mediadores, incentivando o pensamento reflexivo no debate, indo de acordo com a sugestão de Barbosa (2001) para encaminhar a atividade de modelagem a uma perspectiva sócio-crítica.

$\mathrm{Na}$ etapa de apresentação de resultados e discussões, surgiram diversas questões propostas pelos próprios alunos que poderiam ser amplamente desenvolvidas em sala de aula, algumas das quais são apresentadas na sequência.

O grupo responsável por pesquisar e propor soluções para minimizar a geração e destinar corretamente os resíduos trouxe a questão das sacolas reutilizáveis nos supermercados. Essa questão poderia ser quantificada matematicamente em uma próxima etapa: quantas sacolas plásticas são distribuídas, em média, em um supermercado diariamente? E se juntássemos todos os supermercados de Porto Alegre? Qual o impacto ambiental de uma mudança de hábitos, individual e coletiva, neste sentido? O mesmo grupo debateu a questão das embalagens, que deveriam ser projetadas para otimizar a geração de resíduos, diminuindo sua quantidade ao máximo. Essa questão também poderia ser investigada do ponto de vista matemático, trabalhando com geometria, ao pensar formatos de embalagens mais efetivos.

O grupo responsável por estimar a geração de resíduos por pessoa conseguiu trabalhar com os dados apresentados pelo Engenheiro convidado, chegando a um resultado aproximado de massa de resíduo (em $\mathrm{kg}$ ) gerada por dia por habitante. Contudo, ao tentar comparar com o volume de uma lixeira $\left(\mathrm{em} \mathrm{m}^{3}\right)$ se deparou com a questão da densidade do resíduo, quando compactado ou não. Que diferença faz a compactação do 
resíduo em sua densidade? Como calculá-la? Qual o volume ocupado por uma certa quantidade de resíduo, quando compactado ou não? São questões matemáticas que, ao serem exploradas, podem levar não apenas à resolução do problema em si, mas também à compreensão do real volume ocupado pelo resíduo e da importância da conscientização acerca de sua geração e destinação.

O grupo responsável por estudar o Aterro de Minas do Leão encontrou dados sobre a geração de energia através da queima de resíduos. Foram discutidos tópicos interdisciplinares, como por exemplo envolvendo Química: por que queimam os resíduos? Uma possível explicação é de que, ao depositar resíduos orgânicos no aterro, o processo de decomposição torna-se anaeróbio, gerando gás metano, que é muito mais prejudicial ao meio ambiente, em termos de aquecimento global, do que o gás carbônico liberado pela queima. Logo, no momento que o resíduo orgânico é levado ao Aterro, queimá-lo torna-se uma alternativa. Contudo, houve uma discussão, mediada pelos professores, de que poderiam ser estudadas alternativas de compostagem para que parte desses resíduos não fosse levada até lá. De qualquer forma, se os resíduos vão ser queimados, o correto seria aproveitar a energia gerada dessa queima, e é justamente o que estão fazendo no Aterro em estudo, conforme pesquisa do próprio grupo. Este assunto é muito amplo e poderia ser explorado por atividades de modelagem sob diferentes vieses: (i) quantidade de energia gerada na queima de resíduos; (ii) quantificação dos impactos ambientais do metano e do gás carbônico; (iii) quantidade de resíduo orgânico que não iria para o aterro se fossem planejadas usinas de compostagem. É interessante perceber que todas essas questões foram levantadas no momento de debate entre a turma, e como a Modelagem Matemática acaba aparecendo quase que naturalmente.

Por fim, o grupo responsável por debater a localização da estação de transbordo do lixo, localizada atualmente em um ponto não estratégico para minimização da rota dos caminhões até o Aterro, trouxe diversas questões sobre o impacto na população local pela instalação de uma estação de transbordo. Assim, o grupo argumentou que o problema não deveria ser analisado apenas sobre o viés logístico, mas também com um olhar mais amplo, de valorização/desvalorização de bairros e envolvimento com os habitantes, que devem participar da decisão. Nota-se aqui um envolvimento dos membros do grupo no sentido de questionar as situações-problema para além da aplicação formal da matemática, com postura crítica e reflexiva.

A partir da observação da prática realizada, chama-se a atenção da importância de aproximações entre os cursos de Licenciatura e Engenharia, tendo em vista potencialidades mútuas de aprendizagem. Se por um lado o conhecimento técnico do engenheiropesquisador convidado agregou muito aos debates da atividade, por outro o próprio engenheiro teve a oportunidade de trocar ideias com um público diferente, refletindo sobre sua própria prática docente e aprimorando sua formação enquanto engenheiro-professor.

De fato, segundo Muniz (2018), é de suma importância que a formação do engenheiro-professor aconteça para além das titulações de mestrado e doutorado, com uma formação didático-pedagógica continuada, possibilitando o processo de metamorfose desse profissional. A aproximação com cursos de Licenciatura possibilita, assim, que o engenheiro-professor tenha contato com outros públicos e com debates sobre tendências da educação, que podem ser utilizadas e/ou adaptadas para o Ensino Superior. Nesta atividade criou-se um espaço de experimentação pedagógica e reflexão sobre a prática docente, contribuindo para a formação do professor e construindo um ambiente que propiciou o diálogo de saberes. 


\section{CONSIDERAÇÕES FINAIS}

Neste artigo foram abordados princípios teóricos da Modelagem Matemática sob a perspectiva sócio-crítica, e, com base nesses princípios, foi realizado um planejamento de aula, tratando da temática da geração e destinação de resíduos. Através dessa proposta foi possível estabelecer conexões entre a fundamentação teórica e a prática docente, escolhendo-se um tema de grande relevância socioambiental em nossa sociedade.

O planejamento foi colocado em prática através de um experimento piloto, com alunos do curso de Licenciatura em Matemática da UFRGS. Os resultados observados mostraram-se interessantes, gerando discussões ricas e com grande potencial de desenvolvimento dentro da Modelagem Matemática. Observou-se que todos os tópicos abordados seriam plausíveis de serem discutidos com alunos do $3^{\circ}$ ano do Ensino Médio, desde que respeitada a velocidade da turma e sua interação natural com o assunto, convidando os alunos a participarem de uma forma ativa, propondo suas próprias ideias, e se envolvendo como cidadãos conscientes. Em uma próxima etapa dessa pesquisa, almeja-se aplicar o planejamento em uma sala de aula do Ensino Médio, através de uma sequência de encontros.

Ressalta-se também que, dada a resposta ativa dos Licenciandos que participaram da aula, abre-se uma nova possibilidade de um planejamento mais específico para este público, uma vez que a formação crítica, reflexiva e cidadã de futuros professores é essencial para que eles próprios se sintam confortáveis em abordar temas como este em sala de aula. A participação ativa de um engenheiro-pesquisador na atividade agregou muito à discussão, ao mesmo tempo em que complementou sua própria formação enquanto engenheiro-professor, evidenciando as vantagens mútuas de aprendizagem propiciadas pela aproximação entre os cursos de Licenciatura e Engenharia em práticas interdisciplinares que envolvam a Modelagem Matemática.

\section{REFERÊNCIAS}

ARAÚJO, J. L. Uma Abordagem Sócio-Crítica da Modelagem Matemática: a perspectiva da educação matemática crítica. Alexandria Revista de Educação em Ciência e Tecnologia, v. 2, n. 2, p. 55-68, julho 2009.

BARBOSA, J. C. Modelagem na Educação Matemática: contribuições para o debate teórico. In: REUNIÃO ANUAL DA ANPED, 24., 2001, Caxambu. Anais... Rio Janeiro: ANPED, 2001.

BASSANEZI, R. C. Modelagem Matemática - Teoria e Prática. São Paulo: Contexto, 2015. $240 \mathrm{p}$.

BRASIL. Secretaria de Educação Fundamental. Parâmetros curriculares nacionais: Ciências Naturais. Brasília: MEC/SEF, 1998.

BURAK, D. Modelagem matemática: ações e interações no processo de ensinoaprendizagem.1992. 130 f. Tese (Doutorado) - Curso de Matemática, Universidade Estadual de Campinas, Campinas, 1992.

HELLER, E. Caracterização de atores domésticos no processo de coleta seletiva de lixo em Porto Alegre. 2009. 46 f. TCC (Graduação) - Curso de Administração, Universidade Federal do Rio Grande do Sul, Porto Alegre, 2009. 
JACOBINI, O. R.; WODEWOTZKI, M. L. L. Uma Reflexão sobre a Modelagem Matemática no Contexto da Educação Matemática Crítica. Boletim de Educação Matemática, v. 19, n. 25, p. 71-88, 2006.

MUNIZ, S. S. O engenheiro-professor e a metamorfose: a necessidade da formação didático-pedagógica. Revista de Ensino de Engenharia, v. 37, n. 3, p. 95-101, 2018.

OREY, D. C.; ROSA, M. A dimensão crítica da modelagem matemática: ensinando para a eficiência sociocrítica. Horizontes, v. 25, n. 2, p. 197-206, jul/dez 2007.

SILVA, C.; KATO, L. A. Quais Elementos Caracterizam uma Atividade de Modelagem Matemática na Perspectiva Sociocrítica?. Boletim de Educação Matemática, v. 26, n. 43, p. 817-838, ago. 2012.

SKOVSMOSE, O. Prefácio. In: ARAÚJO, J. L. (Org.). Educação Matemática Crítica: reflexões e diálogos. Belo Horizonte: Argvmentvm, 2007.

SUPTITZ, B. Jornal do Comércio. Reciclagem de lixo ainda é desafio para Porto Alegre. 2020. Disponível em:

https://www.jornaldocomercio.com/_conteudo/colunas/pensar_a_cidade/2020/10/763221. Acesso em: 10 maio 2021.

UENO, R.; MORAES, M. S. S. Temas político-sociais no ensino da matemática. Ciência \& Educação, v. 13, n. 2, p. 223-233, 2007. 


\title{
MATHEMATICAL MODELING FROM A SOCIAL-CRITICAL PERSPECTIVE: A DIDACTIC PROPOSAL APPROACHING SOLID WASTE MANAGEMENT IN THE CITY OF PORTO ALEGRE
}

\begin{abstract}
This article addresses an interdisciplinary didactic proposal, presented to students in the Mathematics Education Degree course at the Federal University of Rio Grande do Sul, built under the theoretical framework of Mathematical Modeling from a social-critical perspective. Initially, a bibliographic review was made, approaching the main characteristics and objectives of this educational methodology, with a special focus on the citizenship education. Based on the National Curriculum Parameters, it was emphasized the importance of socio-environmental themes to be approached in classroom in a transversal way, which includes mathematics classes. In this context, a didactic proposal was developed, with the participation of a Civil Engineer, which addresses the management of solid waste in the city of Porto Alegre, aiming to discuss a topic of socio-environmental relevance, allowing the student to be an active subject in the learning process, by reflecting on the social reality and proposing transformative actions. Some relations between the proposed activity and the theoretical references are discussed. Then, it is presented a report of a pilot experiment, carried out in a class of Mathematics Education III, showing the discussions and modeling routes that emerged during the activity, as well as describing some didactic potentialities to be approached in future applications in high school. Finally, it is discussed the importance of the mathematics teacher's formation to include the study of education topics that cover transversal themes, as well as the mutual advantages arising from approximations between the Mathematics Education Degree and Engineering courses.
\end{abstract}

Keywords: Mathematical modeling, social-critical perspective, solid waste management, interdisciplinarity, Engineering, Mathematics Education. 